\title{
Comment
}

Neuroepidemiology 2010;35:100

DOI: $10.1159 / 000310326$

\section{Evidence-Based Medicine and Multiple Sclerosis: Figures and Stories}

\section{Jürg Kesselring}

Department of Neurology and Neurorehabilitation, Rehabilitation Centre, Valens, Switzerland

In this issue of Neuroepidemiology, Lad et al. [1] describe a carefully conducted study on socioeconomic trends in hospitalization for multiple sclerosis (MS) in the USA based on the Nationwide Inpatient Sample of 20,000 admissions to 1,000 hospitals in 37 states. These figures provide an important framework for estimating the socioeconomic dimensions of MS and for planning health care. According to this study, the 'national bill' for MS increased during 1993-2006 from USD 184 million to 445 million annually, and the average annual cost per MS patient increased from USD 8,000 to 20,000 during this period. These appear to be high figures; they could, however, also be translated in terms of solidarity, in that the average US citizen pays USD 1.44 per year or 12 cents per month for his fellow citizen affected by MS. MS is a common neurological disease in young and middle-aged adults. Estimates of prevalence range from 1.11 million to 2.5 million people affected worldwide - 350,000 patients in Western Europe - and crude estimates of lifetime costs of illness are reported as USD 1.6 million. A series of studies on the costs of MS and quality of life in 9 European countries was reported in 2006 in a supplement of the European Journal of Health Economics by Kobelt et al. [2]. It was shown how annual costs increased steeply with increasing disability as measured on the Expanded Disability Status Scale (EDSS): EUR 18,000 at EDSS scores of <4.0, EUR 36,500 at EDSS scores of 4.0-6.5, and EUR 62,000 at EDSS scores of $>7.0$. Similar figures have been produced earlier in Canada with CAD 15,000 for mild disease, CAD 21,000 for moderate disease and CAD 37,000 for severe disease cases [3]. The main economic benefit can therefore only be expected by preventing patients from progressing to advanced disease stages where costs are high and the quality of life is severely impaired. Costs of MS are dominated by factors outside the health care system: productivity loss due to short-term sickness leave and early retirement, nonmedical costs such as those produced by devices and transports and, especially, informal care provided by family and friends. It is estimated that $74-88 \%$ of the real costs are paid by the patient. In a study on costs of disorders of the brain [4], MS showed the second lowest prevalence among 12 disorders of the brain, but the mean annual cost per case was the second highest at EUR 24,000 by purchasing power parity (international measure to compare data from different countries). In this study, the total annual (2004) costs for MS in Europe were estimated at EUR 8,769 million by purchasing power parity $(25 \%$ health care costs, $45 \%$ direct nonmedical costs and 30\% indirect costs). Such figures are useful and important as a basis for understanding the impact of MS as a disease.

Other aspects, however, have to be borne in mind when studying chronic disorders of the nervous system such as MS. When diagnosing and treating patients, there is the other aspect: illness. Neurology is not just a specialty with a great socioeconomic impact and refined diagnostic possibilities but with little to offer in terms of therapeutics. The earlier nomenclature of the WHO, when classifying health conditions and diseases, used terms with negative connotations: disability, handicap. The new framework for classifying health conditions (such as MS), the International Classification of Functioning, Disability and Health, brought a change in names and, thereby, in attitudes [5-7]. This truly marks a paradigm shift. Consequences of a disease process are described at the level of body structures and functions as 'impairments', but the focus is now on 'activities' (which, of course, may be limited due to the disease) instead of the former disabilities, and on the social level, the focus is more on 'participation' (and its limitations) than on handicaps. When dealing with treatment options and prognosis for an individual patient, it is obvious that personal factors from his/her history as well as environmental factors must be considered. Neuroplasticity in the central nervous system is the basis for adaptive changes which occur spontaneously and which may be induced by appropriate therapies. They form the structural and functional correlates of learning and must be applied when dealing with individual patients with chronic neurological disorders such as MS.

\section{References}

1 Lad SP, Chapman CH, Vaninetti M, Steinman L, Green A, Boakye M: Socioeconomic trends in hospitalization for multiple sclerosis. Neuroepidemiology 2010;35:93-99.

2 Kobelt G, Berg J, Lindgren P: Costs and quality of life of multiple sclerosis in Europe. Eur J Health Econ 2006;7(suppl 2):S3-S104.

-3 Canadian Burden of Illness Study Group: Burden of illness of multiple sclerosis. Part 1. Cost of illness. Can J Neurol Sci 1998;25:23-30.

4 Andlin-Sobloki P, Jönsson B, Wittchen H-U, Olesen J: Costs of disorders of the brain. Eur J Neurol 2005;12:1-27.

5 Kesselring J, Coenen M, Cieza A, Thompson A, Kostanjsek N, Stucki G: Developing the ICF Core Sets for multiple sclerosis to specify functioning. Mult Scler 2008;14:252-254.

6 Holper L, Coenen M, Weise A, Stucki G, Cieza A, Kesselring J: Characterization of functioning in multiple sclerosis using the ICF. J Neurol 2010;257:103-113.

7 Kesselring J, Comi G, Thompson AJ: Multiple Sclerosis. Functional Recovery and Neurorehabilitation. Cambridge, Cambridge University Press, 2010, in press.

Prof. Jürg Kesselring

Department of Neurology and Neurorehabilitation

Rehabilitation Centre

$\mathrm{CH}-7317$ Valens (Switzerland)

Tel. +41 81303 1408, Fax +41 813031410

E-Mail j.kesselring@klinik-valens.ch

\section{KARGER}

Fax +41 613061234 E-Mail karger@karger.ch www.karger.com
(2) 2010 S. Karger AG, Basel

0251-5350/10/0352-0100\$26.00/0 